\title{
ANALYSIS ON FAILURE MECHANISM OF SCARF JOINTS WITH BRITTLE- DUCTILE ADHESIVES SUBJECTED TO UNIAXIAL TENSILE LOADS
}

\author{
Lijuan LIAO \\ Institute of Mechanics \\ Chinese Academy of Sciences \\ 15\#, Beisihuan West Road, Beijing \\ 100190, CHINA \\ E-mail: ljl@imech.ac.cn
}

\author{
Toshiyuki SAWA \\ Graduate School of Engineering \\ Hiroshima University \\ 1-4, Kagamiyama, Higashihiroshima, Hiroshima \\ 739-8527, JAPAN \\ E-mail: tsawa@hiroshima-u.ac.jp
}

\author{
Chenguang Huang \\ Institute of Mechanics \\ Chinese Academy of Sciences \\ 15\#, Beisihuan West Road, Beijing \\ 100190, CHINA \\ E-mail: huangcg@imech.ac.cn
}

\begin{abstract}
The failure mechanism of scarf joints with a series of angles and brittle-ductile adhesives subjected to uniaxial tensile loads is analyzed by using a numerical method which employs a cohesive zone model (CZM) with a bilinear shape in mixedmode (mode I and II). The adopted methodology is validated via comparisons between the present simulated results and the existing experimental measurements, which illustrate that the load-bearing capacity increases as the scarf angle decreases. More important, it is observed that the failure of the joint is governed by not only the ultimate tensile loads, but also the applied tensile displacement until complete failure, which is related to the brittle-ductile properties of the adhesive layer. In addition, failure energy, which is defined by using the area of the load-displacement curve of the joint, is adopted to estimate the joint strength. Subsequently, the numerical results show that the strength of the joint adopting ductile adhesive with higher failure energy is higher than that of the joint using brittle adhesive with lower failure energy.
\end{abstract}

\footnotetext{
*Address all correspondence to this author.
}

\section{INTRODUCTION}

With many advantages over conventional mechanical fastening techniques, adhesively joints with light weight and high strength have been attracted in various technological applications, especially in aerospace and automotive industries. Multifarious types of structural adhesively joints with various geometrical configurations are examined to identify their load carrying capacities [1]. The failure the adhesively joints extremely depends on the mechanical properties of the adhesive [2-4] and the stress systems of the adhesive layer imposed by the constraint effect of stiff adherends [5,6]. Owing to the complex failure behavior of the adhesively joints, it is difficult to obtain a universal failure criterion to be applied various situations. According to the research carried by Lucas et al. [2], it can be obtained that the pure elastic or plastic prediction is not enough to depict the essence of the joint strength. In addition, Mohd Afendi et al. [6] also pointed out that the theoretical results using the existing failure criteria (i.e. maximum principal stress and Mises equivalent stress) cannot satisfactorily estimate the experimental results in the scarf joint strength prediction in their research.

Many studies [2-4, 6-8] demonstrated that the failure occurs in the adhesive layer with lower stiffness compared to the adherends. Meanwhile, failure was assumed to take place progressively as energy dissipated gradually at the crack tip [2]. In order to excavate the mechanism of crack propagation, 
cohesive zone model (CZM) coupled with FEM is used widely to visualize the process of failure [2-5, 7-9]. With the advantage of mesh independency, the behavior of the structures up to failure can be characterized by numerical methods with CZM, in which the damage growth is ruled by energetic criteria [7-9].

In the present study, scarf adhesively joint, which enables the uniform distribution of the stresses avoid bending [10], is chosen as the research object. The failure mechanism of the scarf joint under uniaxial tensile loads is analyzed using FEM method (performed in ABAQUS ${ }^{\circledR}$ ) including CZM with a bilinear shape in mixed-mode (mode I and II), which owing to the normal-shear mixed stress state at the scarf interface. To validate the adopted the numerical method, the load-bearing capacity of the adhesively joint with a series of scarf angles is predicted using this FEM method, which are compared with the existing experimental results. More than that, in order to examine the effects of the properties of adhesive layer on the joint failure, two types (brittle and ductile) adhesives are selected. The joint strength, which is described using the stretch energy of the tensile loads (the area of load-displacement curve of the adhesively scarf joint), is also estimated.

\section{NUMERICAL ANALYSIS}

\section{Simulation Models}

Figure 1 shows a two-dimensional (2D) plane-strain model of the scarf adhesively joint for FEM calculations. Two same adherends are joined together using the adhesive layer with the scarf angle $\theta$. The boundary definitions are also can be seen in Fig.1. The free end of the lower adherend is fixed both in $x$ - and $y$-direction. Meanwhile, the free end of the upper adherend is loaded by increasing displacement $u_{y}$ along the $y$-direction. Thus, the uniaxial tensile loads can be simulated, which built with ABAQUS ${ }^{\circledR}$ commercial code. The nonlinear analysis is carried out owing to the large displacement in the adhesive region.

The dimensions of the scarf joints are defined as shown in Fig. 1[11]. For the scarf angle $\theta$, it is chosen as $15^{\circ}, 30^{\circ}, 45^{\circ}$, $52^{\circ}, 60^{\circ}, 75^{\circ}$ and $90^{\circ}$ to examine its effect on the performances of the joint. The material of the adherends is defined as isotropic elastic model using Young's modulus E and Poisson's ratio $v$, which are chosen as $209 \mathrm{GPa}$ and 0.29 [11], respectively. The adhesives are selected as two types: a brittle adhesive (AV138/HV998) and a ductile one (Hysol EA 9361) [2] to examine the effects of the properties of adhesives on the performances of the joint. For the adhesive layer, CZM is adopted to describe the progressive damage based on tractionseparation (T-S) law.

\section{Cohesive zone model}

CZM requires T-S relations for characterizing the constitutive law of the adhesive as interface [2-4, 7-9], in which the peak value (cohesive strength $\sigma_{u}$ ) and area (critical energy release rate $G_{c}$ ) of the T-S curve are vital to capture the interface separation behavior [2-4, 12]. A bilinear T-S law is employed in this study for simplicity [13-15]. Owing to the scarf lap joining interface, a complex stress state of the joint is present with mixed-mode (mode I and II) damage propagation, in which each pure model is shown in Fig.2 [2-4]. The critical energy release rate in each mode at complete failure is described using the area of the triangle in Fig.2 $(i=\mathrm{I}, \mathrm{II})$ :

$$
G_{i}=1 / 2 \sigma_{u, i} \delta_{u, i}
$$

Damage initiation was controlled using a quadratic stress criterion as following,

$$
\left(\sigma_{\mathrm{I}} / \sigma_{u, \mathrm{I}}\right)^{2}+\left(\sigma_{\mathrm{II}} / \sigma_{u, \mathrm{II}}\right)^{2}=1
$$

in which assumed that a pure compressive deformation or stress state does not initiate damage. A linear fracture criterion is adopted to determine the damage propagation, which expressed as:

$$
G^{\mathrm{I}} / G_{\mathrm{I}}+G^{\mathrm{II}} / G_{\mathrm{II}}=1
$$

where $G^{\mathrm{I}}$ and $G^{\mathrm{II}}$ denote work by the traction and its conjugate relative displacement in each mode, respectively.



Figure 1 A MODEL OF SCARF ADHESIVELY JOINT FOR FEM CALCULATIONS WITH DIMENSIONS AND BOUNDARY CONDITIONS (Unit: $\mathrm{mm}$ )

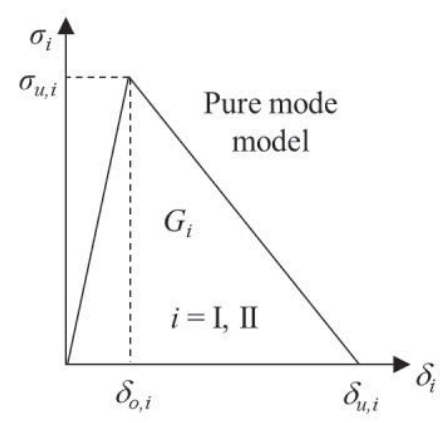

Figure 2 PURE MODES (I, II) DAMAGE MODELS [3, 4] 


\section{Adhesive constitutive parameters in CZM}

Table 1 ADHESIVES CONSTITUTIVE PARAMETERS [2]

\begin{tabular}{|c|c|c|}
\hline Parameters & $\begin{array}{c}\text { AV138/HV998 } \\
\text { (brittle) }\end{array}$ & $\begin{array}{c}\text { Hysol EA } \\
9361 \\
\text { (ductile) }\end{array}$ \\
\hline Young's modulus $E(\mathrm{GPa})$ & 4.59 & 0.67 \\
\hline Poisson's ratio $v$ & 0.35 & 0.4 \\
\hline Yield strength $\sigma_{y a}(\mathrm{MPa})$ & 36.49 & 4.23 \\
\hline $\begin{array}{l}\text { Area of the stress-strain curve } \\
\text { of the adhesive } A_{c}(\mathrm{MPa})\end{array}$ & 0.32 & 4.04 \\
\hline $\begin{array}{l}\text { critical energy release rate } \\
\text { (mode I) } G_{\mathrm{I}}(\mathrm{N} / \mathrm{mm})\end{array}$ & 0.3 & 2.61 \\
\hline $\begin{array}{l}\text { critical energy release rate } \\
\text { (mode II) } G_{\text {II }}(\mathrm{N} / \mathrm{mm})\end{array}$ & 0.6 & 5.22 \\
\hline
\end{tabular}

The bilinear mixed-mode CZM mentioned above is adopted in the analysis to define a $0.1 \mathrm{~mm}$ thickness $\left(t_{a d}\right)$ adhesive layer. For the govern triangle of T-S curve of mixedmode damage, the parameters to be defined are cohesive strength $\sigma_{u, \mathrm{I}}$ (pure mode I) and $\sigma_{u, \mathrm{II}}$ (pure mode II), critical energy release rate $G_{\mathrm{I}}$ (pure mode I) and $G_{\mathrm{II}}$ (pure mode II), and initial stiffness (the initial slope of the damage govern triangle) $k$. The constitutive parameters of the adopted adhesives are listed in Table 1.

According to the previous investigations [2-4, 16], the cohesive strength in each mode can be considered that both equals to the yield strength of the adhesive $\left(\sigma_{u, \mathrm{I}}=\sigma_{u, \mathrm{II}}=\sigma_{y a}\right)$. The adhesive with definite thickness would dissipate energies including the adhesive layer separated $\left(G_{\mathrm{I}}\right.$ and $\left.G_{\text {III }}\right)$ and plastic deformation $G_{\mathrm{p}}$, which is estimated approximately as $t_{a d} A_{c}[3,4$, 17]. In addition, the initial stiffness $k$ is described using $E / t_{a d}$.

The adhesive layer is built as a single layer using four-node cohesive element, which parameters are defined as the methods mentioned above according to brittle-ductile adhesives.

\section{RESULTS AND DISCUSSIONS}

\section{Numerical results}

With the increment of the applied displacement, the tensile loads increase until to the peak point and then decrease to zero. Usually, the ultimate value $\left(F_{u}\right)$ of the uniaxial tensile load can be employed to estimate the load-bearing capacity of the joint. Meanwhile, the displacement corresponding to the ultimate load is denoted as ultimate displacement $u_{u}$.

Figure 3 shows the tensile loads $\left(F_{y}\right)$ vs. displacement $\left(u_{y}\right)$ of the adhesively joint of a series of scarf angles with brittleductile adhesives, where $F_{y}$ is the resultant force of uniaxial tensile loads along the $y$-direction per unit thickness of the joint. It can be seen that the load-bearing capacity of the adhesively joint increases as the scarf angle $\theta$ decreases both with brittle and ductile adhesives. In addition, the ultimate load $F_{u}$ of the joint including brittle adhesive with the given scarf angle $\theta$ is larger than that of the joint selecting ductile one as shown in Fig.3-4. Conversely, the ultimate displacement $u_{u}$ of the joint choosing brittle adhesive is smaller than that of the joint adopting ductile one as shown in Fig.3.



(a) AV138/HV998 (brittle adhesive)

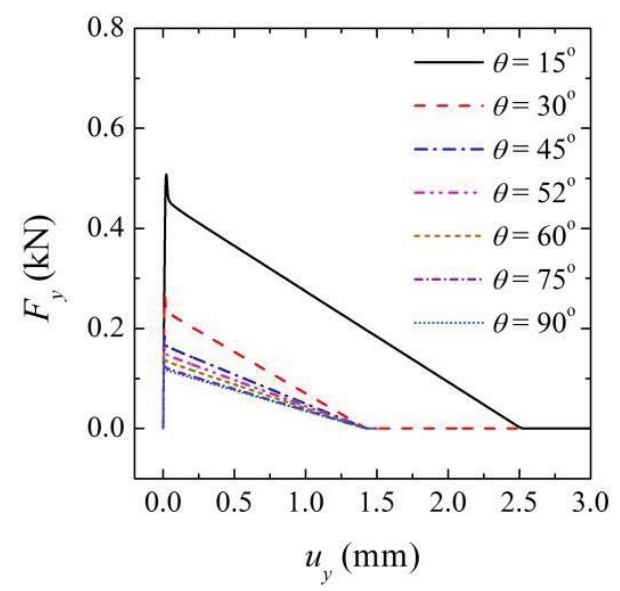

(b) Hysol EA 9361 (ductile adhesive)

Figure 3 LOAD-DISPLACEMENT CURVES OF ADHESIVELY JOINT OF A SERIES OF SCARF ANGLES $\theta$ WITH BRITTLE-DUCTILE ADHESIVES $\left(t_{a d}=0.1 \mathrm{~mm}\right)$

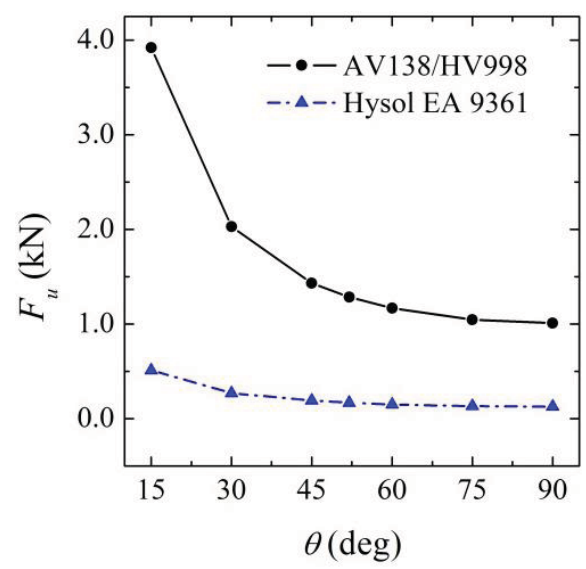

Figure 4 COMPARISONS OF THE ULTIMATE TENSILE LOADS BETWEEN ADHESIVELY SCARF JOINTS WITH BRITTLE AND DUCTILE ADHESIVES 


\section{Discussions}

In CZM, cohesive strength and energy release rate are two vital parameters to describe the separation behavior of the adhesively joint $[3,4]$. It is easy to understand that the loadbearing capacity of the joint using the adhesive with higher cohesive strength $(36.49 \mathrm{MPa}$ - AV138/HV998) is larger than that of the joint combining the adhesive with lower cohesive strength (4.23MPa - Hysol EA 9361).

More than that, as shown in Fig.3, after the load reached the ultimate value of the given scarf angle $\theta$, it drops due to the damaged adhesive layer. For the joint including adhesive AV138/HV998, the uniaxial tensile loads drop to zero sharply with significant brittle property. On the contrary, when the joint selects Hysol EA 9361, the applied loads drop slowly until zero, which present ductile property. The different drop trends are decided by the fracture energy of the adopted adhesives [3, 4]. Except the plastic dissipation energy of the adhesive layer, the cohesive energy of the brittle adhesive $\left(G_{\mathrm{I}}=0.3 \mathrm{~N} / \mathrm{mm}\right.$ and $\left.G_{\text {II }}=0.6 \mathrm{~N} / \mathrm{mm}-\mathrm{AV} 138 / \mathrm{HV} 998\right)$ is much lower than that of the ductile adhesive $\left(G_{\mathrm{I}}=2.61 \mathrm{~N} / \mathrm{mm}\right.$ and $G_{\mathrm{II}}=5.22 \mathrm{~N} / \mathrm{mm}-$ Hysol EA 9361).

For the brittle adhesive, when the applied load reaches the ultimate value, it can be considered that the failure of the adhesive layer occurs without plastic deformation. However, for the ductile adhesive, the sensitive of stress is low even ignorable after the maximum stress arrived, which is the constitutive property. As shown in Fig.3 (b), the load drop trend is so slow that the complete separation occurs subjected to quite large displacement. Thus, the joint strength criterion using the load-bearing capacity is lack of comprehensive consideration.

Owing to the different properties of the brittle-ductile adhesive, more reasonable evaluation method of the adhesively joint strength is necessary. In the present study, the stretch energy, which is described by the work done by the tensile loads according to the displacement until the complete failure occurs, is used to estimate the joint strength. The expression is shown as following:

$$
E_{f}=\int_{0}^{u_{y \max }} F_{y} d u_{y}
$$

where $u_{y \max }$ is the displacement corresponding to the tensile load $F_{y}$ drops from the ultimate value to zero. It equals to the area of the load-displacement curve for given scarf angle and selected adhesive. Figure 5 shows the comparisons of the failure energy $E_{f}$ between adhesively scarf joints with brittle and ductile adhesives. It can be assumed that the strength of the scarf joint with brittle adhesive is smaller than that of the scarf joint using ductile adhesive. Furthermore, it can be obtained that the joint strength is decided both by load-bearing capacity and applied displacement until complete failure.

\section{Validation of numerical method}

In order to verify the present method, the numerical results are compared with the existing results from the previous experimental measurements $[6,10]$, which the comparisons between them can be seen in Fig. 6 .

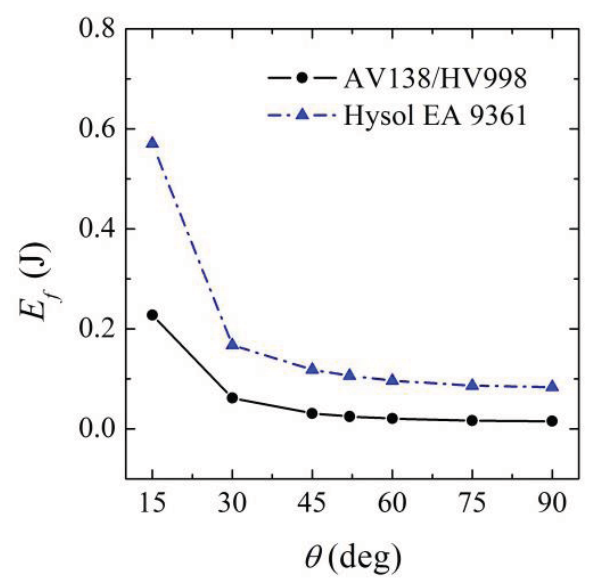

Figure 5 COMPARISONS OF THE FAILURE ENERGY $E_{f}$ BETWEEN ADHESIVELY SCARF JOINTS WITH BRITTLE AND DUCTILE ADHESIVES

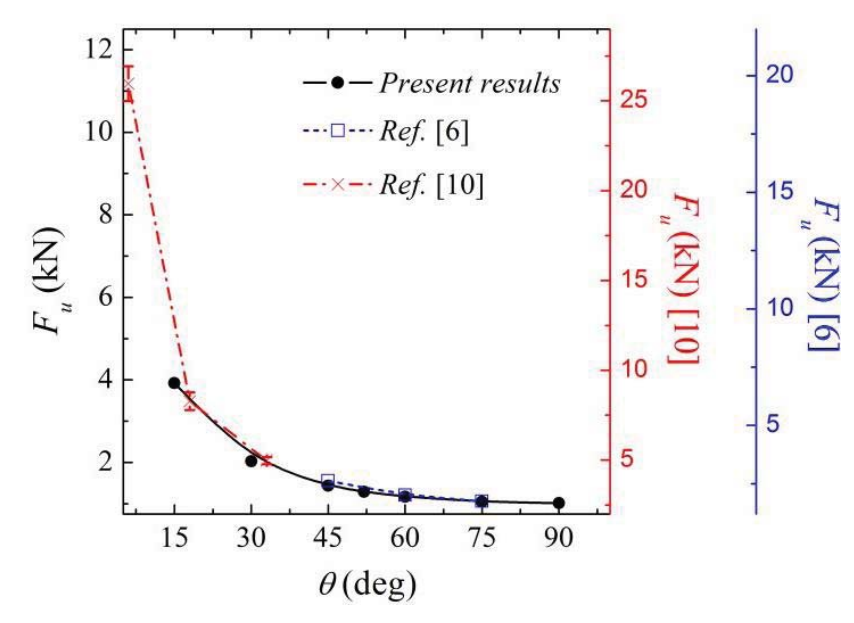

Figure 6 COMPARISONS OF THE ULTIMATE LOADS VS. SCARF ANGLE BETWEEN THE PRESENT RESULTS AND THE EXISTING EXPERIMENTAL MEASUREMENTS

In Mohd Afendi et al.'s research [6], the scarf angles $\theta$ were chosen as $45^{\circ}, 60^{\circ}$ and $75^{\circ}$. Meanwhile, in the study carried by A. Gacoin et al. [10], the scarf angle $\theta$ was selected as $6^{\circ}, 18^{\circ}$ and $33^{\circ}$, respectively. It can be found that the loadbearing capacity of the adhesively joint decreases as the scarf angle $\theta$ increases, which the change trends of the curves according to the scarf angle $\theta$ are similar. It can be concluded that the present simulated method is effective to analysis the failure mechanism of the adhesively joint with various scarf angles and adhesives subjected to tensile loads.

\section{CONCLUSIONS}

In this study, the failure mechanism of scarf joints with a series of angles and brittle-ductile adhesives subjected to uniaxial tensile loads is examined using a numerical method including a cohesive zone model (CZM) with a bilinear shape 
in mixed-mode (mode I and II). The following results are obtained.

(1) The load-bearing capacity, which described using the ultimate value of the applied uniaxial tensile loads, of the adhesively joint increases as the scarf angle decreases.

(2) The load-bearing capacity of the scarf joint adopting brittle adhesive with higher cohesive strength is higher than that of the joint using ductile adhesive with lower cohesive strength.

(3) The applied displacement of the scarf joint containing brittle adhesive with lower energy release rate is quite smaller than that of the joint including ductile adhesive with higher energy release rate.

(4) The failure of the joint is decided by the ultimate tensile load and applied displacement until complete failure together.

(5) The numerical results show that the strength of the joint with ductile adhesive, which described using the failure energy of the uniaxial tensile loads (the area under the load-displacement curve of the joint), is higher than that of the joint with brittle adhesive.

(6) The present simulated method is validated by comparing with the existing experimental results.

\section{ACKNOWLEDGMENTS}

The work presented in this study is supported by the National Natural Science Foundation of China, Grant No. 11202222. The authors would like to express the greatest appreciation to the financial support.

\section{REFERENCES}

[1] Adams R.D., Wake W.C. and Comyn J., Structural joints in engineering. Chapman and Hall, 1997.

[2] Lucas F.M. da Silva, T.N.S.S. Rodrigues, M.A.V. Figueiredo, M.F.S.F. de Moura and J. A. G. Chousal, Effect of Adhesive Type and Thickness on the lap shear strength. The Journal of Adhesion. 82(11), 1091-1115, 2006.

[3] Wei Xu and Yueguang Wei, Strength and interface failure mechanism of adhesive joints. International Journal of Adhesion \& Adhesives, 34, 80-92, 2012.

[4] Wei $\mathrm{Xu}$ and Yueguang Wei, Influence of adhesive thickness on local interface fracture and overall strength of metallic adhesive bonding structures. International Journal of Adhesion \& Adhesives, 40, 158-167, 2013.

[5] T. Pardoen, T. Ferracin, C.M. Landis and F. Delannay, Constraint effects in adhesive joint fracture. International Journal of the Mechanics and Physics of Solids, 53, 19511983, 2005.

[6] Mohd Afendi, Tokuo Teramoto and Hairul Bin Bakri, Strength prediction of epoxy adhesively bonded scarf joints of dissimilar adherends. International Journal of Adhesion \& Adhesives, 31, 402-411, 2011.

[7] Anna Rudawska, Adhesive joint strength of hybrid assemblies: Titanium sheet-composites and aluminium sheet-composites - Experimental and Numerical verification. International Journal of Adhesion \& Adhesives, 30, 574-582, 2010.

[8] R.D.S.G. Campilho, M.F.S.F. de Moura, D.A. Ramantani, J.J.L. Morais and J.J.M.S. Domingues, Tensile behavior of three-dimensional carbon-epoxy adhesively bonded single- and double-strap repairs. International Journal of Adhesion \& Adhesives, 29, 678-686, 2009.

[9] Peter A. Gustafson and Anthony M. Waas, The influence of adhesive constitutive parameters in cohesive zone finite element models of adhesively bonded joints. International Journal of Solids and Structures, 46, 2201-2215, 2009.

[10] A. Gacoin, P. Lestriez, J. Assih, A. objois and Y. Delmas, Comparison between experimental and numerical study of the adhesively bonded scarf joint and double scarf joint: Influence of internal singularity created by geometry of the double scarf joint on the damage evolution. International Journal of Adhesion \& Adhesives, 29, 572579, 2009.

[11] He D., Sawa T., Iwamoto T. and Hirayama Y., Stress analysis and strength evaluation of scarf adhesive joints subjected to static tensile loadings. International Journal of Adhesion \& Adhesives, 30, 387-392, 2010.

[12] Freund L.B. and Suresh S., Thin Film Materials: Stress, Defect Formation and Surface Evolution. Cambridge: Cambridge University Press, 2003.

[13] Li H. and Chandra N., Analysis of crack growth and cracktip plasticity in ductile materials using cohesive zone models. International Journal of Plasticity. 19, 849-882, 2003.

[14] Chandra N. Li H. Shet C. and Ghonem H., Some issues in the application of cohesive zone models for metal-ceramic interfaces. International Journal of Solids and Structures. 39, 2827-2855, 2002.

[15] Ghosh S., Ling Y., Majumdar B. and Kim R., Interfacial debonding analysis in multiple fiber reinforced composites. Mechanics of Materials. 32(10), 561-591, 2000.

[16] M.F.S.F. de Moura, J.P.M. Goncalves, J.A.G. Chousal and R.D.S.G. Campilho, Cohesive and continuum mixed-mode damage models applied to the simulation of the mechanical behaviour of bonded joints. International Journal of Adhesion \& Adhesives, 28, 419-426, 2008.

[17] Y.G. Wei and H.F. Zhao, Peeling experiments of ductile thin films along ceramic substrates - Critical assessment of analytical models. International Journal of Solids and Structures. 45, 3779-3792, 2008. 